\title{
CORPUS Corpus
}

Archivos virtuales de la alteridad americana

Vol 5, No $1 \mid 2015$

Enero / Junio 2015

\section{La Guerra de la Triple Alianza (1865-1870) y la Guerra del Chaco (1932-1935). Dos guerras internacionales en un marco colonial}

Luc Capdevila

\section{OpenEdition}

\section{Journals}

Electronic version

URL: http://journals.openedition.org/corpusarchivos/1399

DOI: 10.4000/corpusarchivos.1399

ISSN: 1853-8037

Publisher

Diego Escolar

\section{Electronic reference}

Luc Capdevila, « La Guerra de la Triple Alianza (1865-1870) y la Guerra del Chaco (1932-1935). Dos guerras internacionales en un marco colonial », Corpus [En línea], Vol 5, No 1 | 2015, Publicado el 29 junio 2015, consultado el 10 diciembre 2020. URL : http://journals.openedition.org/corpusarchivos/ 1399 ; DOI : https://doi.org/10.4000/corpusarchivos.1399

This text was automatically generated on 10 December 2020.

Licencia Creative Commons: Atribución-NoComercial 2.5 Argentina (CC BY-NC 2.5 AR) 


\title{
La Guerra de la Triple Alianza (1865-1870) y la Guerra del Chaco (1932-1935). Dos guerras internacionales en un marco colonial
}

\author{
Luc Capdevila
}

1 Las guerras del Paraguay contemporáneo - la de la Triple Alianza entre 1865 y 1870 y la del Chaco entre 1932 y 1935- son guerras de masas, "de alta intensidad", que tienen por protagonistas a Estados nacionales en construcción o ya formados, y que ocurrieron en el marco de los convenios internacionales en preparación o ya funcionando. Hay que recordar que estas dos guerras internacionales son las más sangrientas que se hayan desarrollado en América durante los siglos 19 y 20. Paraguay casi desapareció durante la primera, y salió victorioso - pero reventado- de su enfrentamiento con Bolivia durante la segunda. En ambos casos Paraguay luchó "a muerte" contra sus vecinos. Por lo tanto, ambos conflictos son eventos matriciales que han participado en la formación del núcleo de la identidad nacional de este país.

2 Ambas guerras han generado relatos históricos patrióticos clásicos y constituyen un fondo simbólico nacional y heroico. Son numerosos los recuerdos de ex combatientes, testimonios, novelas y trabajos académicos que alimentan y organizan esta narrativa nacional de los beligerantes. Sin embargo, no es posible entender estas dos grandes guerras americanas desde una lectura estrictamente nacional (Richard et al. 2007). El contexto colonial es fundamental para entender las formas, las dinámicas y los impactos que supusieron. Es lo que quiero mostrar en el caso del Paraguay, que conozco mejor.

3 Acerca del marco colonial, hacemos nuestra las definiciones de Georges Balandier y de Pablo González Casanova. Es decir que, ya sea un colonialismo imperial o uno interno, se refiere a un orden social marcado por la violencia y la dominación social, cultural, 
económica y política de una sociedad humana sobre otra (Balandier 1951, Casanova 1964). O, como lo precisa Frederick Cooper a propósito de los imperios europeos durante el mismo periodo, la situación colonial corresponde "a un conjunto de prácticas que definieron y reprodujeron en el tiempo la diferenciación y la subordinación de tal pueblo en un territorio particular" (Cooper 2010, p. 40).

Nos parece que hay también una dimensión psico-histórica de la colonización, ya que uno de los efectos de estas relaciones de dominación es la cristalización de comunidades emocionales caracterizadas por un sentimiento mutuo de inseguridad, de desconfianza y de miedo al otro, lo que puede favorecer violencias extremas, imaginadas y perpetradas (Gómez 2013,Joly 2009). Generalmente estas relaciones se forman en sociedades compartimentadas, donde se asocian comunidades distintas, que ven en el otro una alteridad radical. Así que el racismo es una de las expresiones más comunes.

5 Por lo tanto, me parece que las guerras del Paraguay ocurrieron en un contexto colonial que generó formas específicas de guerra que no se suelen encontrar en los conflictos internacionales convencionales, a diferencia de las guerras coloniales, guerras civiles, o de los conflictos internacionales explícitamente no convencionales, como por ejemplo en la segunda guerra mundial en el Este europeo o en el Lejano Oriente, cuando Japón se enfrentó a China.

6 A partir de esta hipótesis, y con relación al cuestionario que se propone para organizar el debate, me gustaría desarrollar tres puntos sobre estos dos conflictos. El primero es la violencia extrema desplegada durante la Guerra de la Triple Alianza. El segundo trata de la construcción de la identidad nacional basada en el mestizaje y el bilingüismo, que se formó en Paraguay durante ambos conflictos. El tercero, analiza la matriz colonial caracterizada por la memoria de la Guerra del Chaco en Paraguay.

\section{El tema de la violencia desplegada durante la Guerra de la Triple Alianza}

7 Todos conocemos la sobremortalidad que caracteriza al Paraguay durante la Guerra de la Triple Alianza. Esta corresponde a un nivel de violencia que no tiene equivalente en el siglo 19 y 20 en los conflictos convencionales (Doratioto 2004, Capdevila 2010, Whigham 2010/2013). En cambio, estos niveles de mortandad sí se corresponden con los de guerras civiles o conflictos coloniales. Sin embargo, la Guerra del Paraguay se da en un marco convencional real y en parte operativo. Las élites lo proclamaron. También es observable en el tratamiento de los prisioneros de guerra, en el discurso sobre la guerra y en la movilización que prepara la guerra (discurso de los diplomáticos, declaraciones públicas, pactos) y al terminar el conflicto (juicio, comité de arbitraje, tratado, comisión de investigación para determinar las responsabilidades).

De hecho, la Guerra de la Triple Alianza ha conocido formas híbridas. Por un lado, porque más allá de la contienda entre los Estados, hay actores autónomos que practican una guerra de captura. Muchas paraguayas siguieron a los vencedores, se casaron con soldados brasileños o argentinos y este dato no ha producido una 'memoria de la vergüenza' en Paraguay. Existen también algunas evidencias de captura y de negocio de niños fomentados por oficiales uruguayos (Casal 2004). Del mismo modo, el reclutamiento de los prisioneros de guerra fue común, en particular de parte de 
Argentina y sobre todo de Uruguay. Al final de la guerra, el 80\% del ejército uruguayo se compone de prisioneros paraguayos reclutados (Casal 2004).

9 La naturaleza híbrida del conflicto se nota también en el uso de la violencia. Su uso es diferente según la figura del enemigo. La violencia es extrema, exagerada a través de la mutilación de cadáveres o el asesinato de caballos, cuando se trata de enfrentamientos entre indios aliados de la Triple Alianza y soldados paraguayos (Taunay 1913). Entre los beligerantes nacionales la violencia varía según las fases de la guerra. Por ejemplo, es fuertísima, por el lado brasileño, a partir de la invasión del territorio paraguayo, lo que puede explicar la resistencia absoluta de una parte del ejército y de la sociedad paraguaya.

10 Sobre todo, se verifica la importancia, o la inercia de una cultura colonial en los discursos de movilización y en la designación del enemigo, a través del racismo y del proceso de animalización usados para dibujar la figura del enemigo. El miedo al otro y el sentimiento de la amenaza recíproca del exterminio son generalizados. Se nota también cómo en la práctica los oficiales construyen y transmiten la idea de la alteridad absoluta del enemigo. Podemos observarlo con la actitud de los oficiales paraguayos para convencer a sus compatriotas de que los presos de la triple alianza son animales. Exponiéndolos y tratándolos como animales. Por ejemplo, sirviéndolos la comida en un mismo recipiente, en el suelo, como si fueran cerdos ${ }^{1}$.

11 Sin embargo, igual que en la sociedad colonial, hay una cercanía cultural relativa entre las comunidades. Se la puede observar por ejemplo en el uso plural de los idiomas. Más allá de la práctica común del español, a menudo la prensa paraguaya usa el guaraní cuando los paraguayos toman la palabra, y utiliza el portugués para hacer hablara los brasileños (Johansson 2014). La proximidad cultural se observa también con los numerosos casamientos que siguen a la agresión y a la ocupación militar. Como ya lo dijimos, centenares de soldados aliados se casaron al final de la guerra con paraguayas ${ }^{2}$.

Estos diferentes elementos recuerdan las prácticas y la estructura del antiguo régimen colonial caracterizado por las castas y por lo tanto por el mestizaje y por la fluidez de las identidades mestizas como circulación de una casta a otra. Recuerdan también que el teatro de esta guerra se organiza sobre el sistema de fallas de las antiguas fronteras coloniales. Frontera entre el Imperio portugués y el Imperio Español, bajo presión de las incursiones bandeirantes. Frontera entre el intendente de Asunción y las misiones, sobre la que se desataron las guerras jesuíticas. Frontera entre el espacio colonial y el desierto del Chaco, frecuentemente vulnerada por malones. Efectivamente, el contexto colonial es histórico y cultural (Capdevila 2014). Lo que se observa en los imaginarios y en las prácticas. En consecuencia, nos parece que todo eso ha llevado a una guerra "sin igual en el mundo", como decían los testigos en la década de 1880 (Truquin 1977, p. 252).

\section{La construcción de una identidad nacional basada en el mestizaje y el bilingüismo}

Una guerra de alta intensidad es un acontecimiento mayor-traumático - que impacta a varias generaciones. Produce así identidades colectivas. Podemos hablar en este sentido de etnogénesis o, en otra escala, de naciogénesis. Son mecanismos culturales bien conocidos. Estos momentos de intensa agresividad producen la cristalización de un 
entre-sí dispuesto a matar y a morir para defender una identidad (Anderson 1996), que también se construye en oposición a un enemigo percibido como el único agresor. Paraguay ha sido profundamente impactado por estos dos conflictos. Ambos generaron una identidad colectiva fuerte, sobre la base de una memoria colectiva viva, un nacionalismo muy interiorizado, sin concesiones, y una cultura introvertida que desconfía de los vecinos (Capdevila 2012).

Sin embargo, es interesante observar que el contenido de esa identidad que aparece en la Guerra de la Triple Alianza, que ha sido teorizado por los intelectuales nacionalistas entre 1900 y 1930 y que se ha reforzado en la Guerra del Chaco, es la idea de un pueblo mestizo bilingüe, con el español como lengua del Estado y el guaraní como idioma de connivencia. De facto, los estereotipos nacionales, con los que fueron designados los vecinos en la guerra, también se basan en una supuesta unidad de raza y de lengua: los brasileños son vistos como negros (kambá, es decir 'asado') de lengua portuguesa, los argentinos (kurepí), es decir con la piel rosada (como los cerdos) e hispanohablantes. Mientras que en la Guerra del Chaco, el enemigo boliviano es designado como indio andino, a veces hispanohablante o de idioma aymará (Capdevila 2007).

Lo importante es que, en relación con la construcción del Estado nacional y la formación de la identidad nacional basada en la unidad de raza y de lengua, se oculta en el imaginario colectivo que antes de la guerra la comunidad paraguaya era en realidad plural: con blancos, mestizos, negros (pardos) y sobre todo con indios, ya que los llamados "pueblos históricos" que existían hasta los años 1850 eran en realidad las antiguas misiones jesuíticas (Boidin 2011). La presencia de afro descendientes en la sociedad paraguaya es percibida por la mayoría, en el siglo 20 , como la huella infamante de las violaciones cometidas por los soldados brasileños, mientras que los negros eran una pequeña minoría en el ejército brasileño, debido al régimen de la esclavitud que lo caracterizaba. En cuanto a los indios del vecindario, se designan con la categoría colonial moderna de "indígena", igual que en el resto de la región, a partir del siglo 20.

16 Así que la guerra ha producido la representación de un entre-sí, basado sobre la autoctonía americana nativa y la diferencia radical con los vecinos mediante la valorización del mestizaje biológico y lingüístico (el jopará), y por otra parte la convocación a categorías coloniales estereotipadas, de castas, para construir la imagen del vecino enemigo (negro brasileño, indio boliviano, blanco argentino). Una vez más, se observa que este imaginario nacional se ha cristalizado en un marco geopolítico y cultural heredado de un campo de fallas colonial.

\section{La matriz colonial que caracteriza la memoria paraguaya de la Guerra del Chaco}

17 La Guerra del Chaco ocurrió en un contexto colonial aún mayor. Como en la Guerra de la Triple Alianza, la contienda fue percibida como una gran guerra patriótica. Sin embargo, a diferencia de la Guerra de la Triple Alianza, el teatro de la guerra es estrictamente un "desierto colonial". El conflicto es sobre todo una guerra de colonización, en la medida en que el acontecimiento guerrero corresponde principalmente a la ocupación de territorios de poblaciones indígenas autónomas y a la 